\title{
Heterogeneity of CYP3A isoforms metabolizing erythromycin and cortisol
}

\begin{abstract}
The $N$-demethylation of erythromycin and $6 \beta$-hydroxylation of cortisol are both functions of the glucocorticoid-inducible CYP3A in human liver microsomes. To determine whether $6 \beta$-hydroxylation and erythromycin $\mathrm{N}$-demethylation are catalyzed by similar or distinct CYP3A isoforms, erythromycin $\mathrm{N}$-demethylase activity, as reflected by the recently described ${ }^{14}[\mathrm{C}]$-erythromycin breath test, was compared with urinary $6 \beta$-hydroxycortisol/cortisol ratios, a measure of cortisol $6 \beta$-hydroxylase activity, in nine patients. Erythromycin $N$-demethylation varied fourfold and $6 \beta$-hydroxycortisol/cortisol ratios varied sevenfold among the subjects; no correlation was found between these activities $\left(r^{2}=0.065\right)$. New

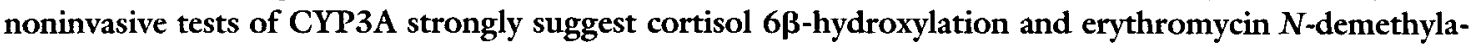
tion are performed by distinct CYP3A isoforms. (Clin Pharmacol Ther 1992;51:18-23.)

\author{
Christine M. Hunt, MD, ${ }^{a}$ Paul B. Watkins, MD, Paul Saenger, MD, \\ Gregg M. Stave, MD, JD, MPH, Neal Barlascini, MD, Charles O. Watlington, MD, \\ Jackson T. Wright, Jr., MD, and Philip S. Guzelian, $\mathbf{M D}^{\mathbf{b}}$ \\ Richmond, Va., Ann Arbor, Mich., and Bronx, N.r.
}

The hepatic cytochromes P450 are a supergene family of microsomal hemoproteins that oxidize lipophilic compounds to polar metabolites for excretion into bile and urine. Characterizations of the human liver cytochromes P450 have revealed at least nine distinct gene families. ${ }^{1}$ The glucocorticoid-inducible human hepatic CYP3A gene family consist of at least four closely related hemoproteins. ${ }^{2-9}$ The hepatic CYP3A superfamily includes family members CYP3A3 (formerly known as HLp), CYP3A4 (hPCN1 or P450NF), CYP3A5 (hPCN3), and CYP3A6 (HLp2 or HFLa). The isoforms CYP3A3 and CYP3A4 metabolize clinically important drugs, including erythromycin, nifedi-

From the Department of Medicine, Medical College of Virginia, Richmond; the Department of Medicine, University of Michigan, Ann Arbor; and the Department of Pediatrics, Montefiore Medical Center, Bronx.

Supported by grants AM-18976 and ES-03699 from the National Institutes of Health (Bethesda, Md.).

Received for publication July 1, 1991; accepted Aug. 28, 1991.

Reprint requests: Christine M. Hunt, MD, Box 3064, Duke University Medical Center, Durham NC 27710.

${ }^{a}$ Supported by an Associate Investigator's Award from the Veterans Administration (McGuire VA Medical Center, Richmond, Va.) and by an American Liver Foundation Post-Doctoral Fellowship Award.

'Recipient of the Burroughs Wellcome Toxicology Scholar Award (Richmond, Va.).

13/1/33447

18 pine, cyclosporine, midazolam, quinidine, troleandomycin, and clotrimazole. ${ }^{1}$ Important endogenous substrates, such as testosterone and glucocorticoids, also undergo CYP3A-catalyzed metabolism to their respective $6 \beta$-hydroxylated derivatives in humans ${ }^{4,5}$ and rats. ${ }^{10-12}$

The two major human liver CYP3A isoforms, CYP3A3 and CYP3A4, are encoded by distinct genes; however, these two genes and proteins are so similar that these forms cannot be reliably distinguished by oligonucleotide hybridization studies ${ }^{13,14}$ or immunochemical detection. ${ }^{15}$ By use of noninvasive tests of human hepatic CYP3A function, we sought to determine whether identical or distinct isoforms of the CYP3A gene family performed cortisol $6 \beta$-hydroxylation and erythromycin $N$-demethylation. These activities were examined by (1) urinary 6 $\beta$-hydroxycortisol/cortisol ratios and (2) the $\left[{ }^{14} \mathrm{C}\right]$-erythromycin breath test, respectively. The urinary $6 \beta$-hydroxycortisol/cortisol ratio corrects for changes in glucocorticoid production rates and therefore more closely reflects rates of hepatic cortisol $6 \beta$-hydroxylation. ${ }^{16,17}$ On the basis of the observation that erythromycin is a specific substrate for the hepatic CYP3A, ${ }^{6,18}$ Watkins et al. ${ }^{18}$ recently showed that measurement of exhaled ${ }^{14} \mathrm{CO}_{2}$ after administration of $\left[{ }^{14} \mathrm{C}\right]$-erythromycin provides a specific and reproducible noninvasive measurement of the amounts of the hepatic immunoreactive CYP3A and erythromycin $\mathrm{N}$-demethylase activity in liver mi- 
Table I. Measurement of urinary $6 \beta$-hydroxycortisol/cortisol ratios and $\left[{ }^{14} \mathrm{C}\right]$-erythromycin metabolism at 60 minutes in subjects with hypertension

\begin{tabular}{|c|c|c|c|c|c|c|c|c|}
\hline $\begin{array}{l}\text { Patient } \\
\text { No. }\end{array}$ & $\begin{array}{l}\text { Age } \\
(y r)\end{array}$ & Gender & Race & $\begin{array}{l}\text { Ideal body } \\
\text { weight }(\%)\end{array}$ & $\begin{array}{c}24-\mathrm{Hr} \text { urine } \\
6 \beta-\mathrm{OH} \\
\text { cortisol } \\
\text { (mg/day) }\end{array}$ & $\begin{array}{l}\text { Ratio of } \\
\text { urinary } 6 \beta-O H \\
\text { cortisol/cortisol }\end{array}$ & $\begin{array}{l}\% \text { Total }{ }^{14} \mathrm{C}- \\
\text { erythromycin } \\
\text { metabolism } \\
(60 \mathrm{~min})\end{array}$ & Medications \\
\hline 1 & 45 & Female & Black & 110 & 222.7 & 8.7 & 4.0 & None \\
\hline 2 & 65 & Female & Black & 121 & 158.1 & 5.3 & 3.1 & $\begin{array}{l}\text { Ibuprofen, glyburide hy- } \\
\text { drochlorothiazide, } \\
\text { chlorazepate dipotassium }\end{array}$ \\
\hline 3 & 57 & Female & White & 139 & 443.5 & 7.4 & 2.6 & $\begin{array}{l}\text { Atenolol, triamterene, } \\
\text { hydrochlorothiazide, } \\
\text { calcium }\end{array}$ \\
\hline 4 & 47 & Female & Black & 147 & 360.0 & 14.2 & 2.3 & Gemfibrozil, atenolol \\
\hline 5 & 52 & Female & Black & 174 & 222.7 & 28.6 & 2.0 & $\begin{array}{l}\text { Propanolol, hydrochlor- } \\
\text { othiazide }\end{array}$ \\
\hline 6 & 50 & Female & White & 223 & 386.4 & 14.6 & 1.0 & Chlorthalidone \\
\hline 7 & 72 & Male & White & 97 & 219.8 & 9.6 & 2.1 & $\beta$-Blocker study drug \\
\hline 8 & 67 & Male & White & 115 & 363.6 & 6.6 & 1.9 & $\beta$-Blocker study drug \\
\hline 9 & 50 & Male & White & 185 & 198.0 & 3.9 & 1.7 & Diltiazem, atenolol, aspirin \\
\hline
\end{tabular}

crosomes. Moreover, because erythromycin decreases the clearance of methylprednisolone in humans, ${ }^{19}$ it seemed reasonable to propose that cortisol $6 \beta$-hydroxylation and erythromycin $N$-demethylation may be performed by the same or similar CYP3A isoform(s). To examine this possibility, the erythromycin $N$-demethylation activity was measured by the $\left[{ }^{14} \mathrm{C}\right]$-erythromycin breath test in a convenience sample of nine patients with hypertension whose cortisol $6 \beta$-hydroxylase activity was previously characterized. Despite the abundant evidence for a common catalyst for these reactions, we conclude that erythromycin $N$-demethylation and cortisol $6 \beta$-hydroxylation proceed by distinct pathways in humans.

\section{MATERIAL AND METHODS}

$\left[{ }^{14} \mathrm{C}\right]-N$-Methyl-erythromycin and Aquasol scintillation cocktail were obtained from Du Pont Diagnostic Imaging Division (North Billerica, Mass.). Methylbenzethonium hydroxide and thymolphthalein were obtained from Sigma Chemical Co. (St. Louis, Mo.).

Patient selection. A group of 28 patients (age range, 45 to 72 years) recently diagnosed with hypertension were prospectively enrolled in the study as paid volunteers. All patients had diastolic blood pressures between 90 and $110 \mathrm{~mm} \mathrm{Hg}$ on at least two separate occasions. Patients who exhibited cardiac disease, pulmonary disease, or diabetes mellitus were excluded from the study. (All patients underwent determination of plasma renin and aldosterone to exclude primary hyperaldosteronism or hyperreninemic state before inclusion in the study.) Informed consent was obtained from each patient in accordance with a protocol approved by the Medical College of Virginia Committee for the Conduct of Human Research (Richmond, Va.). Each volunteer had a plasma free cortisol determination at $8 \mathrm{AM}$ and a 24-hour urine collection for cortisol, $6 \beta$-hydroxycortisol, and creatinine determination. All antihypertensive medications were discontinued for at least 1 month before plasma and urine cortisol and $6 \beta$-hydroxycortisol collections. After successful completion of these tests, patients received antihypertensive medications as deemed appropriate by their private physician. The patients were subsequently asked to participate in the $\left[{ }^{14} \mathrm{C}\right]$-erythromycin breath test protocol. A convenience sample of nine of the 28 volunteers consented to participate in the $\left[{ }^{14} \mathrm{C}\right]$-erythromycin breath test protocol.

Measurement of urinary $6 \beta$-hydroxycortisol. Urinary free cortisol was measured at Hazelton Laboratory, Vienna, Va., by radioimmunoassay. Urinary $6 \beta-$ hydroxycortisol values were determined by the laboratory of $P$. Saenger by use of a radioimmunoassay. ${ }^{16}$ A single patient's urine (patient 9) underwent urinary $6 \beta$-hydroxycortisol and cortisol profiling by HPLC analysis, following the method of Kishida and Fukushima. ${ }^{20}$

$\left.{ }^{14} \mathrm{C}\right]$-Erythromycin breath test protocol. The $\left[{ }^{14} \mathrm{C}\right]-N$-methyl-erythromycin breath test protocol was performed in a manner identical to previously published methods. ${ }^{18}$ Ideal body weight was determined by comparison with charts obtained from the Society 


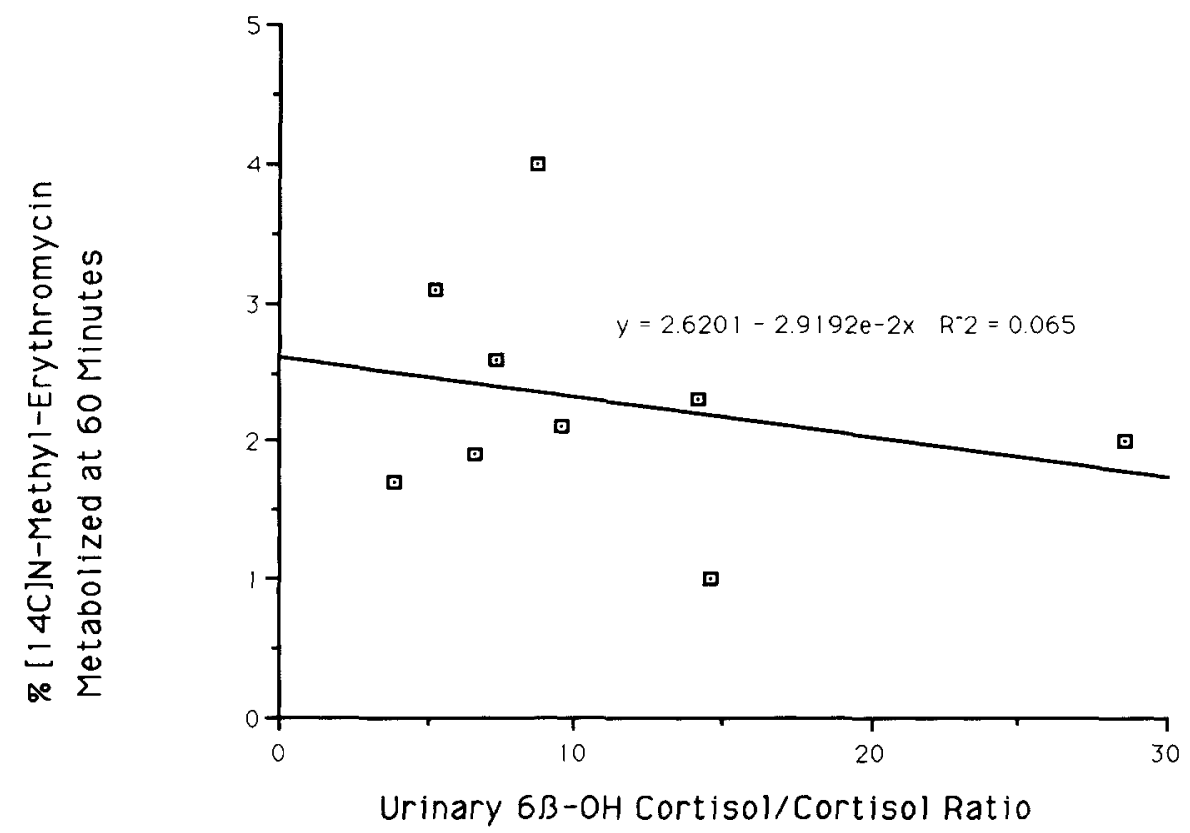

Fig. 1. Nine volunteers underwent a 24-hour urine collection for cortisol, $6 \beta$-hydroxycortisol, and creatinine determination. Urinary free cortisol was measured at Hazelton Laboratory, Vienna Va., by radioimmunoassay. Urinary $6 \beta$-hydroxycortisol values were determined by the laboratory of $P$. Saenger by radioimmunoassay. ${ }^{18}$ Results were expressed as the ratio of urinary $6 \beta$-hydroxycortisol/cortisol. The $\left[{ }^{14} \mathrm{C}\right]-\mathrm{N}$-methyl-erythromycin breath test protocol was performed as described previously. ${ }^{20}$ Regression analyses were used to assess the relationship between $6 \beta$-hydroxycortisol/cortisol ratios and $\left[{ }^{14} \mathrm{C}\right]$-erythromycin clearance.

of Actuaries and Association of Life Insurance Medical Directors of America, 1979 Build Study. ${ }^{21}$

Statistical analyses. Regression analyses were used to assess the relationship between $6 \beta$-hydroxycortisol/cortisol ratios and $\left[{ }^{14} \mathrm{C}\right]$-erythromycin clearance and to evaluate the effect of the potential confounders of age, gender, race, and percentage of ideal body weight. Differences between group means were assessed with the Student $t$ test.

\section{RESULTS}

Plasma free cortisol ( $8 \mathrm{AM}$ ) was normal in the nine patients with newly detected hypertension participating in this study (results not shown). From measurements of $6 \beta$-hydroxycortisol and of cortisol in 24-hour urine collections obtained in these patients, $6 \beta$ hydroxylase activity was estimated as the ratio of urinary $6 \beta$-hydroxycortisol and cortisol (6 6 -hydroxycortisol/cortisol). As described previously, this ratio corrects for changes in glucocorticoid production rates and therefore more closely reflects rates of cortisol $6 \beta$-hydroxylation. ${ }^{16,17}$ The urinary $6 \beta$-hydroxycortisol/cortisol ratios ranged from 3.9 to 28.6 (sevenfold) among the patients (Table I). This range is similiar to previously measured control values in adults. ${ }^{26}$ No significant association was found between age, gender, or race and the ratio of urinary $6 \beta$-hydroxycortisol/cortisol.

The patients then underwent $\left[{ }^{14} \mathrm{C}\right]$-erythromycin breath test analyses between 9 and 11 AM (within 2 hours of breakfast). $\left[{ }^{14} \mathrm{C}\right]$-Erythromycin $N$-demethylation curves revealed a fourfold difference in the ${ }^{14} \mathrm{CO}_{2}$ production among patients. Of the total administered dose of $\left[{ }^{14} \mathrm{C}\right]-\mathrm{N}$-methyl-erythromycin, $1.0 \%$ to $4.0 \%$ was detected as ${ }^{14} \mathrm{CO}_{2}$ exhaled in the first hour (Table I). The amount of ${ }^{14} \mathrm{CO}_{2}$ exhaled after 2 hours was $2.0 \%$ to $4.9 \%$ of the total administered dose. This range of values is not significantly different from published results of $\left[{ }^{14} \mathrm{C}\right]$-erythromycin breath tests carried out on subjects without hypertension. ${ }^{18}$ The $\left[{ }^{14} \mathrm{C}\right]$-erythromycin breath test results, expressed as a percentage of total dose of $\left[{ }^{14} \mathrm{C}\right]-N$-methyl-erythromycin metabolized at 60 minutes, and the urinary $6 \beta$ hydroxycortisol/cortisol ratio showed no statistical association (Fig. $1 ; r^{2}=0.065$ ).

Of the medications being taken by the participants, 


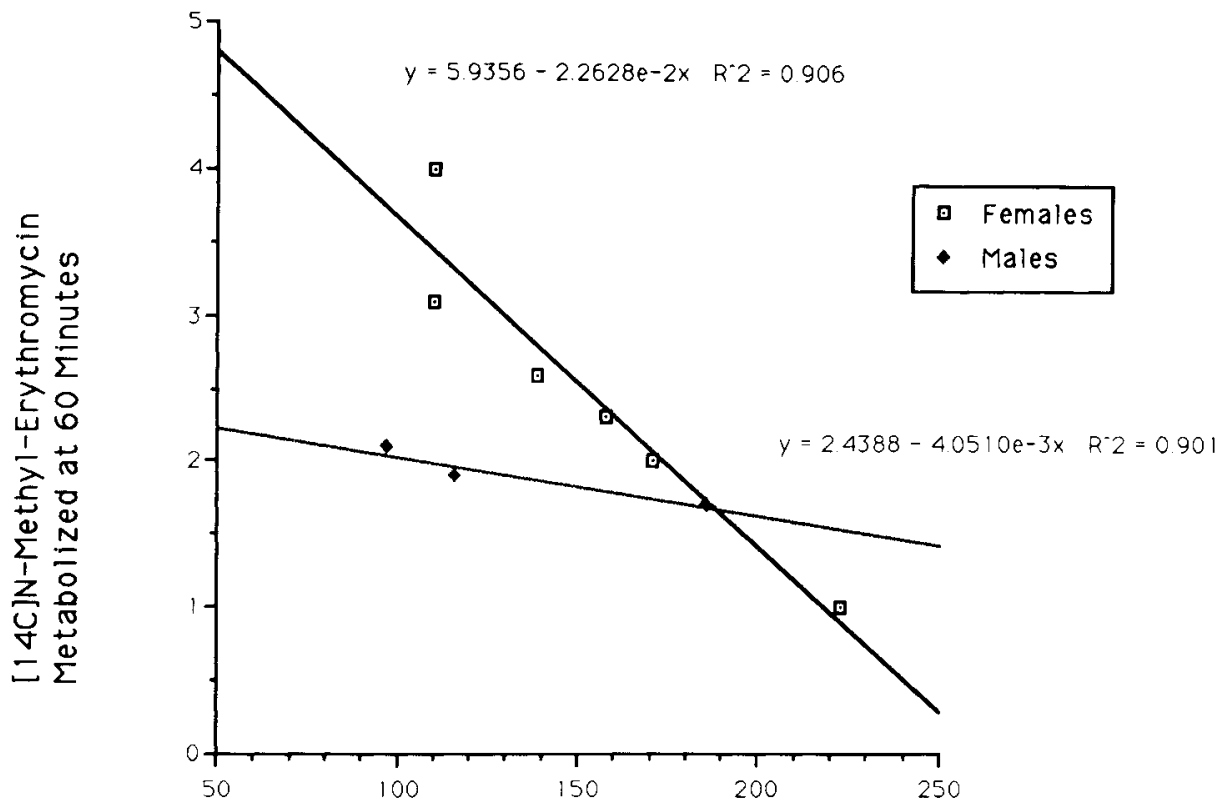

\% Ideal Body Weight

Fig. 2. The $\left[{ }^{14} \mathrm{C}\right]-N$-methyl-erythromycin breath test protocol was performed as described previously ${ }^{20}$ in nine volunteers. Ideal body weight was determined by comparison with charts obtained from the Society of Actuaries and Association of Life Insurance Medical Directors of America, 1979 Build Study ${ }^{23}$ Regression analyses were used to assess the relationship between $\left[{ }^{14} \mathrm{C}\right]$-erythromycin $\mathrm{N}$-demethylation and percentage of ideal body weight, when examined by gender.

only the diltiazem ingested by patient 9 could potentially interfere with this study by competitively inhibiting CYP3A and reducing ${ }^{14} \mathrm{CO}_{2}$ production. ${ }^{23} \mathrm{~Pa}$ tient 9 displayed the lowest $\left[{ }^{14} \mathrm{C}\right]$-erythromycin metabolism of the men tested and the lowest urinary $6 \beta$-hydroxycortisol/cortisol ratio.

No significant gender-dependent difference in erythromycin $\mathrm{N}$-demethylation was detected in this small patient population $(p=0.36)$. However, it was observed that percentage of ideal body weight was significantly negatively associated with the metabolism of $\left[{ }^{14} \mathrm{C}\right]-\mathrm{N}$-methyl-erythromycin at 60 minutes in both men and women (Fig. $2 ; r^{2}=0.91$ in women; $r^{2}=$ 0.90 in men). When the effect of percentage of ideal body weight was compared with the $\left[{ }^{14} \mathrm{C}\right]-N$-methylerythromycin metabolism at 60 minutes in the group as a whole, the correlation was less remarkable $\left(r^{2}=\right.$ $0.46)$. Even though the single obese male patient was also receiving treatment with diltiazam, a calcium channel blocker metabolized by CYP3A, ${ }^{23}$ exclusion of this subject from the analyses still left a negative correlation between $\left[{ }^{14} \mathrm{C}\right]$-erythromycin $\mathrm{N}$-demethylation and percentage of ideal body weight $\left(r^{2}=0.42\right)$.
However, when urinary $6 \beta$-hydroxycortisol/cortisol ratios were compared with percentage of ideal body weight, this ratio was not found to show an association $\left(r^{2}=0.15\right)$.

\section{DISCUSSION}

The most striking finding was the lack of correlation $\left(r^{2}=0.065\right)$ between our estimates of $6 \beta$ hydroxylation and of erythromycin $N$-demethylation in each subject, even though these catalytic activities are supported by CYP3A-related isoforms in human liver microsomes. ${ }^{5,6,18}$ This suggests that closely related but separate CYP3A isoforms in the liver mediate these two activities. Studies of an anhepatic man strongly support the conclusion that the $\left[{ }^{14} \mathrm{C}\right]$-erythromycin breath test largely reflects CYP3A4-catalyzed erythromycin $N$-demethylation in the liver. ${ }^{24}$ However, extrahepatic CYP3A-related cytochromes have been detected immunohistochemically in human kidney, small intestine, polymorphonuclear leukocytes, pancreas, gall bladder, skin, testes, and ovaries ${ }^{25}$ and could account for a significant amount of urinary excretion of $6 \beta$-hydroxycortisol. 
The $\left[{ }^{14} \mathrm{C}\right]$-erythromycin breath test, performed in this small group of patients with hypertension exhibited similiar rates of $\left[{ }^{14} \mathrm{C}\right]-\mathrm{N}$-methyl-erythromycin metabolism at 60 and 120 minutes to those obtained for a hospitalized population. ${ }^{18} \mathrm{~A}$ fourfold range of values was seen in both patient groups. Patients with hypertension exhibited a range of values (sevenfold variation) in urinary $6 \beta$-hydroxycortisol/cortisol ratios similar to results from patients without hypertension. ${ }^{26}$ Preliminary studies had revealed increased hepatic cortisol $6 \beta$-hydroxylase activity, as reflected by urinary $6 \beta$-hydroxycortisol/cortisol ratios, ${ }^{16}$ in a subset of patients with essential hypertension, most of whom were black (Watlington CO, Wright JT, Grogan WM. Unpublished observations, July 1990). However, despite the suggestion that $6 \beta$-hydroxycortisol evokes hypertension, ${ }^{27-29}$ the measured parameters of $6 \beta$ hydroxycortisol production did not support this hypothesis within this group of patients with hypertension. This may be attributable to the wide variety of etiologic factors that contribute to hypertension, in addition to $6 \beta$-hydroxycortisol, as well as a sampling artifact attributable to the small size of our patient population.

The $\left[{ }^{14} \mathrm{C}\right]$-erythromycin $N$-demethylation activity showed a strong negative association with percentage of ideal body weight but no association with $6 \beta-$ hydroxylase activity. This finding suggests the intriguing possibility that specific CYP3A isoforms may decrease in obese subjects. It would be desirable to confirm this novel observation with additional techniques to exclude such alternative explanations as an expansion of the body's formaldehyde pool, resulting in a lower apparent rates of ${ }^{14} \mathrm{CO}_{2}$ production. Increases in total hepatic cytochrome $\mathrm{P} 450$ content, as well as the ethanol-inducible CYP2E1, have recently been described in a strain of obese rats. ${ }^{30}$ The possibility that obesity resulted in the reciprocal repression of other isoforms, a commonly observed effect of induction, was not examined. The present approach of using noninvasive methods holds promise as a way to elucidate the roles that obesity and other previously unrecognized factors play in explaining interindividual variations in the expression of the human liver cytochromes $\mathrm{P} 450$.

\section{References}

1. Gonzalez FJ. Molecular genetics of the P-450 superfamily. Pharmacol Ther 1990;45:1-38.

2. Molowa DT, Schuetz EG, Wrighton SA, et al. Complete cDNA sequence of a cytochrome P-450 inducible by glucocorticoids in human liver. Proc Natl Acad Sci USA 1986;83:5311-5.

3. Guengerich FP, Martin MV, Beaune PH, Kremers P, Wolff T, and Waxman DJ. Characterization of rat and human liver microsomal cytochrome P-450 forms involved in nifedipine oxidation, a prototype for genetic polymorphism in oxidative drug metabolism. $\mathrm{J}$ Biol Chem 1986;261:5051-60.

4. Kitada M, Kamataki T, Itahashi K, Rikihisa T, Kanakubo Y. Significance of cytochrome P-450 (P-450 HFLa) of human fetal livers in the steroid and drug oxidations. Biochem Pharmacol 1987;36:453-6.

5. Waxman DJ, Attisano C, Guengerich FP, and Lapenson DP. Human liver microsomal steroid metabolism: identification of the major microsomal steroid hormone $6 \beta$-hydroxylase cytochrome P-450 enzyme. Arch Biochem Biophys 1988;263:424-36.

6. Watkins $\mathrm{PB}$, Wrighton SA, Maurel $\mathrm{P}$, et al. Identification of an inducible form of cytochrome P-450 in human liver. Proc Nat1 Acad Sci USA 1985;82:6310-4.

7. Wrighton SA, Molowa DT, Guzelian PS. Identification of a cytochrome P-450 in human fetal liver related to glucocorticoid-inducible cytochrome P-450 HLp in the adult. Biochem Pharmacol 1988;37:3053-5.

8. Wrighton SA, Ring BJ, Watkins PB, Vandenbranden $M$. Identification of a polymorphically expressed member of the human cytochrome P-450III family" Mol Pharmacol 1989;36:97-105.

9. Aoyama T, Yamano S, Waxman DJ, et al. Cytochrome P-450 hPCN3, a novel cytochrome P-450 IIIA gene product that is differentially expressed in adult human liver. J Biol Chem 1989;264:10388-95.

10. Cheng KC, Schenkman JB. Testosterone metabolism by cytochrome P-450 isozymes RLM3 and RLM5 and by microsomes. Metabolite identification. J Biol Chem 1983;258:11738-44.

11. Waxman DJ, Dannan GA, Guengerich FP. Regulation of rat hepatic cytochrome P-450: age-dependent expression, hormonal imprinting, and xenobiotic inducibility of six specific isoenzymes. Biochemistry 1985;24: 4409-17.

12. Waxman DJ, Ko A, Walsh C. Regioselectivity and stereospecificity of androgen hydroxylations catalyzed by cytochrome P-450 isozymes purified from phenobarbital-induced rat liver. J Biol Chem 1983;258: 11937-47.

13. Schuetz JD, Molowa DT, Guzelian PS. Characterization of cDNA encoding a new member of the glucocorticoid-response cytochromes $\mathrm{P} 450$ in human liver. Arch Biochem Biophys 1989;274:355-65.

14. Bork RW, Muto T, Beaune PH, et al. Characterization of mRNA species related to human liver cytochrome P-450 nifedipine oxidase and the regulation of catalytic activity. J Biol Chem 1989;264:910-9.

15. Beaune PH, Umbenhauer DR, Bork RW, Lloyg RS, Guengerich FP. Isolation and sequence determination of 
a cDNA clone related to human cytochrome P-450 nifedipine oxidase. Proc Natl Acad Sci USA 1986; 83:8064-8.

16. Saenger $P$. 6 $6 \beta$-Hydroxycortisol in random urine samples as an indicator of enzyme induction. Clin PharmaCOL THer 1983;34:818-21.

17. Roots I, Holbe R, Hovermann W, Nigam S, Heinemeyer $\mathrm{G}$, and Hildebrandt AG. Quantitative determination by HPLC of urinary $6 \beta$-hydroxycortisol, an indicator of enzyme induction by rifampicin and antiepileptic drugs. Eur J Clin Pharmacol 1979;16:63-71.

18. Watkins P, Murray SA, Winkelman LG, Heuman DM, Wrighton SA, Guzelian PS. The erythromycin breath test as an assay of glucocorticoid-inducible liver cytochromes P-450. J Clin Invest 1989;83:68897.

19. LaForce CF, Szefler SJ, Miller MF, Ebling W, Brenner $M$. Inhibition of methylprednisolone elimination in the presence of erythromycin therapy. J Allergy Clin Immunol 1983;72:34-9.

20. Kishida S, Fukushima DK. "Radioimmunoassay of $6 \beta$ hydroxycortisol in human plasma and urine. Steroids 1977;30:741-9.

21. Alpers DH, Clouse RE, Stenson WF. Manual of nutritional therapeutics. (Source of basic data: 1979 Build Study, Society of Actuaries and Association of Life Insurance Medical Directors of America). Boston: Little, Brown, 1985:150.

22. Austin KL, Mather LE, Philpot CR, McDonald PJ. Intersubject and dose-related variability after intravenous administration of erythromycin. Br J Clin Pharmacol 1980;10:273-9.

23. Pichard L, Gillet G, Fabre I, et al. Identification of the rabbit and human cytochromes P-450IIIA as the major enzymes involved in the $\mathrm{N}$-demethylation of diltiazem. Drug Metab Dispos 1990;18:711-9.

24. Watkins PB, Kolars JC, Merion RM, Campbell DA, Fishman K, Saenger P. Erythromycin and $6 \beta-O H$ cortisol: studies in 32 patients and in an anhepatic man" Clin Res 1989;32:342A.

25. Murray GI, Barnes TS, Sewell HF, et al. The immunocytochemical localisation and distribution of cytochrome P-450 in normal human hepatic and extrahepatic tissues with a monoclonal antibody to human cytochrome P-450. Br J Clin Pharmacol 1988;25: 465-75.

26. Ohnhaus EE, Breckenridge AM, Park BK. Urinary excretion of $6 \beta$-hydroxycortisol and the time course measurement of enzyme induction in man. Eur $\mathbf{J}$ Clin Pharmacol 1989;36:39-46.

27. Watlington CO, Atkins JL, McNeal JS, Grogan WM, Johnson JP. Corticosterone is converted to $6 \beta$-hydroxycorticosterone in rat: effects of the metabolite on urinary electrolyte excretion. J Steroid Biochem 1988; 31:947-54.

28. Yamaji T, Motohashi K, Morakara S, et al. Urinary excretion of $6 \beta$-hydroxycortisol in states of altered thyroid function. J Clin Endocrinol Metab 1969;29:801-6.

29. Grogan W, Fidelman M, Newton D, Duncan R, Watlington $\mathrm{CO}$. A corticosterone metabolite produced by A6 (toad kidney) cells in culture: identification and effects on sodium transport. Endocrinology 1985; 116:1189-94.

30. Salazar DE, Sorge CL, Corcoran GB. Obesity as a risk factor for drug-induced organ injury. VI. Increased hepatic P-450 concentration and microsomal ethanol oxidizing activity in the obese overfed rat. Biochem Biophys Res Commun 1988;157:315-20.

\section{Bound volumes available to subscribers}

Bound volumes of Cunical Pharmacology \& Therapeumics are available to subscribers (only) for the 1992 issues from the Publisher, at a cost of $\$ 51.00$ for domestic, $\$ 67.57$ for Canadian, and $\$ 64.00$ for international subscribers for Vol. 51 (January-June) and Vol. 52 (July-December). Shipping charges are included. Each bound volume contains a subject and author index and all advertising is removed. Copies are shipped within 60 days after publication of the last issue of the volume. The binding is durable buckram with the journal name, volume number, and year stamped in gold on the spine. Payment must accompany all orders. Contact Mosby-Year Book, Inc., Subscription Services, 11830 Westline Industrial Drive, St. Louis, MO 63146-3318, USA; phone (800)325-4177, ext. 4351, or (314)453-4351.

Subscriptions must be in force to qualify. Bound volumes are not available in place of a regular journal subscription. 